\title{
Aa., Vv., Victor Hugo 7, le théâtre et l'exil, Florence Naugrette (dir.)
}

\section{Olivier Bara}

\section{(2) OpenEdition}

1 Journals

Édition électronique

URL : https://journals.openedition.org/studifrancesi/4738

DOI : 10.4000/studifrancesi.4738

ISSN : 2427-5856

Éditeur

Rosenberg \& Sellier

\section{Édition imprimée}

Date de publication : 1 avril 2012

Pagination : 166-167

ISSN : 0039-2944

\section{Référence électronique}

Olivier Bara, « Aa., Vv., Victor Hugo 7, le théâtre et l'exil, Florence Naugrette (dir.) », Studi Francesi [En

ligne], 166 (I | LVI) | 2012, mis en ligne le 30 novembre 2015, consulté le 19 novembre 2021. URL :

http://journals.openedition.org/studifrancesi/4738 ; DOI : https://doi.org/10.4000/studifrancesi.4738

Ce document a été généré automatiquement le 19 novembre 2021.

\section{(c) (1) (9)}

Studi Francesi è distribuita con Licenza Creative Commons Attribuzione - Non commerciale - Non opere derivate 4.0 Internazionale. 


\title{
Aa., Vv., Victor Hugo 7, le théâtre et l'exil, Florence Naugrette (dir.)
}

\author{
Olivier Bara
}

\section{RÉFÉRENCE}

AA. VV. Victor Hugo 7, le théâtre et l'exil, Florence NAUGRETTE (dir.), «La Revue des Lettres modernes», Caen, Lettres modernes Minard, octobre 2009, pp. 316.

1 «Théâtre en liberté», «second théâtre», «théâtre de l'exil»: la création dramatique de Victor Hugo durant le Second Empire forme un continent à la géographie mouvante, aux frontières incertaines, faute d'une définition éditoriale des contours du vivant de l'auteur. Comme le rappelle l'Avertissement du présent volume, la première édition, partielle, de ce théâtre a été publiée un an après la mort de Hugo (chez Hetzel et Quantin); elle a d'abord imposé une délimitation restreinte du corpus, limité à quelques pièces en vers (La Grand'Mère, L'Épée, Mangeront-ils?, Sur la lisière d'un bois, Les Gueux, Etre aimé, La Forêt mouillée). En 2002, année du bicentenaire, Arnaud Laster a livré en Folio Gallimard l'édition cette fois la plus extensive du Théâtre en liberté, y intégrant les pièces en prose (L'Intervention, Mille Francs de récompense), ainsi que des pièces en vers comme Les Deux Trouvailles de Gallus et Torquemada. Toute édition fixe artificiellement les formes d'un théâtre fantôme, dont la plasticité, où se lit l'étonnante créativité de Hugo exilé, n'est pas la moindre qualité.

2 L'intérêt du numéro construit par Florence Naugrette consiste à laisser ouvert le champ des possibles et à intégrer dans ce «théâtre de l'exil» les adaptations dramatiques de l'œuvre hugolienne réalisées pendant son absence (Les Misérables par Paul Meurice et Charles Hugo) ou la reprise de son théâtre à Paris, après une longue interdiction, en 1867 (Hernani), puis en 1870 (Lucrèce Borgia). Est même donné en Annexe (par Marie-Pierre ROOTERING, pp. 299-313) le tableau des droits d'auteur de Victor Hugo pendant l'exil, montrant que son œuvre dramatique demeure présente sur les scènes, au moins à travers ses adaptations lyriques. Le Théâtre en liberté, au lieu d'être considéré 
comme une œuvre secrète, à usage personnel, coupée de la scène contemporaine, étrange hapax dans l'histoire du théâtre du XIX ${ }^{e}$ siècle, se trouve ainsi réinscrit dans la création dramatique vivante de son temps, et replacé dans la continuité du théâtre écrit entre 1827 et 1843. En ce sens, le volume se place dans le sillage de la très belle thèse de Stéphane DESVIGNES, Le Second Théâtre de Victor Hugo, réalisée sous la direction de Guy RosA à l'université Paris VII en 2006.

C'est justement Stéphane DESVIGNES qui ouvre la première partie du volume, intitulée «Hugo et la scène». En présentant Hugo comme la «mauvaise conscience du théâtre du Second Empire» (pp. 13-33), l'auteur montre comment le fantôme Hugo hante la scène de son temps pour y contester les présupposés fondateurs: la séparation du littéraire et du politique (refus de l'art pour l'art) et la spécialisation de l'écriture théâtrale conçue dans sa spécificité (la «pièce bien faite» chère au critique Sarcey). Ainsi, Hugo organise à distance «un acte de résistance politique et une contestation poétique du théâtre contemporain» (p.29). Sylvie VIELLEDENT (pp. 35-54) décrit ensuite un exemple de ce mode singulier de présence-absence de Hugo sur les scènes, à travers l'adaptation des Misérables réalisée en 1863 par son fils Charles, assisté du fidèle Paul Meurice. Interdite à Paris, la pièce, «populaire par le sujet» mais «conformiste par la forme» (p. 50), fut créée à Bruxelles; elle éclaire en retour le caractère «dramatique» du roman de Hugo. Autre présence-absence: celle de l'auteur d'Hernani, drame repris en 1867 à la ComédieFrançaise dans le cadre de l'Exposition universelle. Jacqueline RAZGonNIKov (pp. 55-69) offre une étude très détaillée des conditions politiques, institutionnelles, esthétiques, culturelles (et mondaines) de cet événement, qui aurait dû être prolongé par la reprise de Ruy Blas à l'odéon. Cet article est complété par la reproduction d'un inédit: l'article consacré à la reprise d'Hernani par Mario Proth dans «L'Europe» en juin 1867, présenté avec une magnifique érudition par Jean-Marc HOVASSE (pp. 249-297). Dernier mode de présence hugolienne sur les scènes, pendant l'interdiction de ses pièces: le répertoire adapté de son œuvre, dont l'auteur gère les droits à distance, non sans difficultés face à la séparation entre droit de représentation et droit de publication, et en l'absence de législation européenne (Marie-Pierre ROOTERING, pp. 71-85).

La deuxième partie du volume, "Écrire Le Théâtre en liberté», propose une approche littéraire, esthétique, stylistique, socio-politique et métaphysique du «second théâtre»; le croisement de ces lectures respecte parfaitement la nature du geste créateur de Hugo: un théâtre, même écrit solitairement dans l'exil, demeure une œuvre de la Cité, pour la Cité et pour l'humanité. Sylvain LEDDA (pp. 89-103) étudie le traitement de la mort de la sorcière dans la comédie Mangeront-ils?. Il rattache le double enjeu de la pièce («survivre quand on a faim en se nourrissant d'amour, mourir avec un sentiment d'accomplissement», p. 91) à la thématique fédératrice de la "puissance des faibles». Arnaud LASTER (pp. 105-120) esquisse une étude de la caractérisation des personnages par leur langage, centrée sur les quatre pièces écrites entre 1865 et 1869 . Deux pièces, Mille Francs de récompense et L'Intervention, sont privilégiées par Danièle GASIGLIA-LASTER pour cerner la représentation de «la femme» (pp. 121-135). Mélanie voisin (pp. 159-170) propose quant à elle une synthèse des études menées sur l'illusion et sa dénégation dans Mangeront-ils? et Mille Francs de récompense. Deux articles remarquables dominent cette partie littéraire du numéro: celui de Sylviane ROBARDEY-EPPSTEIN (pp. 137-157) revient sur la notion de "distanciation", appliquée selon une vision rétrospective au théâtre «pré-brechtien» de Hugo - l'auteur suggère très intelligemment que ces jeux de rupture d'illusion sont hérités des théâtres populaires, en particulier des parodies et 
des vaudevilles contemporains; l'article de Franck LAURENT consacré aux «trois espaces de Torquemada» (pp.171-194) montre l'évolution des «motifs de pensée et de représentation de l'éthique politique» depuis le théâtre d'avant l'exil, les acteurs de l'État devenant «les figures d'un pouvoir sans véritable aura, dont la grandeur même est petite, l'éthique faible, et qui règne sur un espace confus et vain» (p. 180) - le drame dit «la fragilité profonde des sociétés politiques modernes» (p.186), espace immanent que seul l'amour anime.

5 Une dernière partie clôt le volume, "Paroles de metteurs en scène». Les entretiens passionnants (et illustrés) avec Jean-Marie VILLEGIER, Julien TEPHANY et Françoise SPIESS sont salutaires: ils démontrent «en actes» que Le Théâtre en liberté n'est pas une simple fantaisie littéraire à lire dans un fauteuil, mais forme une œuvre théâtrale vivante, puissante et, aujourd'hui même, pertinente. 